\title{
Outcomes of patients with Severe Acute Respiratory Infections (SARI) admitted to the intensive care unit: results from the Egyptian Surveillance Study 2010-2014
}

\author{
Usama E. Abu Elhassan, ${ }^{1}$ Sherif A.A. Mohamed, ${ }^{2}$ Magda S. Rizk, ${ }^{3}$ Mai Sherif, ${ }^{4}$ Mohamed El-Harras ${ }^{5}$ \\ ${ }^{1}$ Department of Chest Diseases, Faculty of Medicine, Cairo University, Cairo \\ ${ }^{2}$ Department of Chest Diseases and Tuberculosis, Faculty of Medicine, Assiut University, Assiut \\ ${ }^{3}$ Department of Anesthesia and Intensive Care, Faculty of Medicine, Cairo University, Cairo \\ ${ }^{4}$ Department of Clinical Pathology, Faculty of Medicine, Cairo University, Cairo \\ ${ }^{5}$ Department of Clinical Pathology, Faculty of Medicine, Mansura University, Mansura, Egypt
}

\begin{abstract}
Background: Few data exist about respiratory viral infections in Egyptian patients. Hereby we describe the outcomes of hospitalized Egyptian patients with severe acute respiratory infections (SARI) admitted to the ICU.

Methods: A prospective study in which all hospitalized patients meeting the WHO case definition for SARI and admitted to the ICU, during the period 2010-2014, were enrolled. Samples were tested using RT-PCR for influenza A, B, respiratory syncytial virus (RSV), human metapneumovirus (hMPV), parainfluenza virus, adenovirus, bocavirus, enterovirus, and rhinovirus. Data were analyzed to study the clinical features of SARI-ICU patients and which pathogens are related to severe outcomes. Associated comorbidities were evaluated using Charlson Age-Comorbidity Index (CACI).

Results: Out of 1,075 patients with SARI, 219 (20.3\%) were admitted to the ICU. The highest rates were reported for RSV (37\%). SARI-ICU patients had higher rates of hospital stay, pneumonia, respiratory failure, ARDS, and mortality. Multivariate logistic regression analysis identified associated respiratory disorders $(p=0.001)$, radiological abnormalities $(\mathrm{p}=0.023)$, and longer hospital stay $(p=0.005)$ as risk factors for severe outcomes.

Conclusions: This surveillance study showed that $20 \%$ of hospitalized Egyptian patients with viral SARI needed ICU admission. SARI-ICU patients had higher rates of hospital stay, pneumonia, respiratory failure, ARDS, and mortality. Higher comorbidity index scores, radiological abnormalities, and longer hospital stay are risk factors for severe outcomes in SARI-ICU patients in our locality.
\end{abstract}

Key words: Clinical outcomes; viral infections; SARI; ICU, Egypt, surveillance.

Correspondence: Sherif A.A. Mohamed, Associate Professor of Pulmonary Medicine, Department of Chest Diseases and Tuberculosis, Faculty of Medicine, Assiut University, 71516 Assiut, Egypt. Tel. +20.882413713 - Fax: +20.88241333327. E-mail: saawm220@gmail.com

Contributions: UEAE, SAAM, MSR, contributed to the draft of the article, revised it critically for important content, and made substantial contributions to conception and design, as well as data acquisition, analysis, and interpretation; UEAE, SAAM, MS, ME, contributed to the draft of the submitted article and made substantial contributions to acquisition, analysis, and interpretation of clinical and clinical pathological data. All authors have provided approval of the manuscript to be published and have agreed to be accountable for all aspects of the work in ensuring that questions related to the accuracy or integrity of any part of the work are appropriately investigated and resolved.

Conflict of interest: The authors have no competing interests.

Funding: This research did not receive any specific grant from funding agencies in the public, commercial, or not-for-profit sectors.

Availability of data and materials: The datasets used and/or analyzed during the current study are available from the corresponding author on reasonable request.

Ethics approval and consent to participate: The study protocol was approved by the Institutional Review Board at the NAMRU-3, as well as the ethical committee of Cairo University Hospital (CUH), in compliance with all applicable federal U.S. regulations governing the protection of human subjects. Informed written consent was obtained from the patients (in the case of adult patients) or patients' parent/legal guardian (in the case of pediatric patients).

Consent for publication: Not applicable. 


\section{Introduction}

The 2009 influenza pandemic had highlighted the need for more global data on severe influenza disease, so the WHO recommended conducting surveillance for hospitalized severe acute respiratory infection (SARI), as well as influenza-like illness (ILI) in outpatients [1-4]. SARI surveillances are now conducted in many countries around the world; however, because of limited resources, they are only conducted in limited settings in the Middle East and Egypt [5-7].

Despite that the roles of different respiratory viruses in the etiology of SARI are becoming clear [8], the presence of a virus does not imply either a more benign clinical course or that systemic inflammatory responses or complications will not happen [9]. Moreover, the true impact of viral infections in the etiology of SARIs requiring hospitalization and intensive care unit (ICU) admission is still unknown [10]. Obtaining accurate information on the epidemiology of critically ill SARI patients and how they are managed should help intensive care practitioners to understand the factors associated with progression from acute respiratory infection to more severe critical illness $[7,9,10]$.

In our previous work [11], we had addressed the clinical characteristics and outcomes of Egyptian adult and pediatric patients with SARI prospectively enrolled at Cairo University Hospitals (CUH) from 2010 to 2014. In the current study, we analyze data of those SARI patients admitted to the ICU. We aimed to investigate the role of different respiratory viruses in causing critical illness requiring ICU admission, which pathogens were related to severe outcomes, and to address the impacts of SARI on the clinical outcomes of patients admitted to the ICU, in terms of morbidity and mortality.

\section{Methods}

\section{Study population}

Cairo University Hospital (CUH) is a 5100-beds tertiary referral teaching hospital. Hospitalized adults (defined as age $\geq 18$ years old), as well as pediatric patients (age $<18$ years old), who were admitted into CUH with the diagnosis of SARI and provided a respiratory sample, from February 2010 to February 2014, were prospectively enrolled. Due to an annual review by dedicated investigators and updates to WHO guidelines, the case definition for SARI had evolved over the study period. Before February 2010, as a global-surveillance case definition of SARI did not exist, the definition for SARI was adapted from the WHO protocol on the rapid response for persons $\geq 5$ years old [1], whereas, for children $<5$ years old, SARI definition was adapted from the program for Integrated Management of Childhood Illness [2]. After March 2011, the global standards and tools for influenza surveillance developed by the WHO were adopted [3]. As of January 2014, the WHO surveillance case definition for SARI was implemented [4] as follows, acute respiratory infection with history of fever or measured fever of $\geq 38^{\circ} \mathrm{C}$, and cough, with onset within the last 10 days, and requiring hospitalization [4]. An enrollment form was used to collect data from enrolled eligible patients including patient demographics, medical history, clinical signs and symptoms, the indication for ICU admission, comorbidities, reported influenza vaccine status, recent travel history, treatment, clinical course, the method and indication of respiratory support, complications, and outcome. Patients with incomplete medical records were excluded. Associated comorbidities (if any) were evaluated using the Charlson Age-Comorbidity Index (CACI) [12]. For comparative purposes, and according to whether the patients were admitted to the ICU or not, they were divided into 2 groups; those admitted to the ICU (SARI-ICU) and those not admitted (SARI non-ICU).

\section{Clinical samples and viral detection techniques}

Nasopharyngeal (NP) and oropharyngeal (OP) swabs for detecting viruses and blood cultures for detecting bacteria were taken from eligible patients on admission using operating procedures described by the WHO [13]. Specimens were taken an average of 7 days after illness onset (range: 1-66 days).

Total nucleic acid (TNA) was extracted by the automated KingFisher Flex Magnetic Particle Processor (Thermo Scientific, Waltham, MA, USA) using MagMAX Total Nucleic Acid Isolation Kit (Cat No. AM 1840, Applied Biosystems, Foster, CA, USA) according to the manufacturer's instructions. The viral target was amplified using specific primers and probes produced by the CDC (Atlanta, GA, USA) and following standard protocol for reverse transcription polymerase chain reaction detection. From 2010 to 2012, testing for RSV, adenovirus, human parainfluenza viruses (hPIV) 1, 2 and 3, influenza (A and B) and human metapneumovirus was conducted at CUH laboratory and sent for confirmation by the Naval Medical Research Unit No.3 (NAMRU-3) laboratory. From 2013 to 2014, testing was conducted at CUH laboratory. For all samples, the human RNase P gene (RP) was tested as an internal positive control to ensure proper sample collection and nucleic acid extraction. Samples were considered positive to the viral target if the amplification curve crossed the threshold line before cycle 40 . All clinical samples should be positive to RP with cutoff value $\leq 37$, as prescribed previously [7]. Blood samples were collected for detection of Mycoplasma pneumonia, Chlamydia pneumonia, and Legionella pneumophila, using RT-qPCR.

\section{Ethical standards}

Prior to study initiation, the study protocol was reviewed and approved by Institutional Review Board at the NAMRU-3, as well as the ethical committee of $\mathrm{CUH}$, in compliance with all applicable federal U.S. regulations governing the protection of human subjects. Informed written consent was obtained from the patients or patients' parent/legal guardian (in case of pediatric patients).

\section{Statistical analysis}

Data analyses were conducted using the software SPSS (Statistical Package for the Social Science; IBM Corp., NY, USA); ver. 22. Data were summarized using median (range) for quantitative variables and number and percent for qualitative variables. Comparison between groups was done using the Chi-square test for qualitative variables, independent sample $t$-test for normally distributed quantitative variables, while the Mann-Whitney U test was used for quantitative variables that are not normally distributed. Indicators of severe disease were assessed for each pathogen of interest using Mantel-Haenszel estimates to calculate odds ratios and confidence intervals and the Mantel-Haenszel chisquared test to assess statistical significance [14]. Logistic regression was used to examine associations between viral respiratory pathogens and severe outcomes, defined as illness requiring ventilation or resulting in death while controlling for demographic and clinical characteristics. All tests were two-sided, and differences with $p<0.05$ were considered significant.

\section{Results}

\section{Demographic data of the study population}

Out of 3,207 participants enrolled in this SARI surveillance, 
$1,075(33.5 \%)$ had positive results for one or more tested viruses. Out of those 1,075 patients, $219(20.3 \%)$ were admitted to the ICU (SARI-ICU group). They included 116 (53\%) females and $103(47 \%)$ males. The median age was 3 years (range $0-85$ years). Children less than 18 years had a significantly higher viral etiology (157 patients, $72 \%$ ) compared to that in adults $(62,28 \%) ; p=0.000$. The highest rates of viral infections were reported for RSV $(82 / 219,37 \%)$, multiple viruses $(41 / 219,19 \%)$, influenza $(36 / 219$, $16 \%)$, and adenovirus $(22 / 219,10 \%)$, respectively. Figure 1 shows these details. Reasons for ICU admission were: lower respiratory tract infection; LRTI $(63 / 219,29 \%)$, severe wheezing with respiratory distress $(27 / 219,12 \%)$, and respiratory failure that required respiratory support $(129,59 \%)$. One hundred patients $(45 \%)$ needed mechanical ventilation (MV), either non-invasive $(n=23)$ or invasive $(\mathrm{n}=77)$. Indications for non-invasive MV were acute nonhypercapnic respiratory failure due to pneumonia in 5 patients, respiratory failure due to cardiogenic pulmonary oedema ( 3 patients), acute hypercapnic respiratory failure due to acute exacerbation of chronic obstructive pulmonary disease (AECOPD) in 8 patients, and acute severe asthma ( 7 patients). Indications for invasive MV were: acute respiratory distress syndrome (ARDS) 15 patients, acute or acute-on chronic respiratory failure due to neuromuscular disorders (24 patients), the presence of contraindication(s) to NIV (22 patients), and no response to initial NIV (16 patients). The smoking rate was significantly higher in ICU than non-ICU patients $(12 \%$ vs $3 \%, p=0.034)$ (Table 1$)$.

\section{Clinical and radiological characteristics in SARI-ICU vs non-ICU patients}

In comparison to non-ICU SARI patients (856/1,057, 79.7\%), SARI-ICU ones had significantly less predominant signs and symptoms at presentation. Particularly, they had less viral prodromal symptoms, as well as, wheezes, nasal congestion, and sputum production ( $p=0.000$ each). ICU pediatric patients had significantly higher viral load than adults $(p=0.000)$, which was also observed among individual viral pathogens (except for PIV). SARI-ICU patients with influenza had significant signs and symptoms at presentation in comparison to non-influenza ones, followed by those with RSV and multiple viral infections, in comparison to non-RSV, and single viral infections, respectively. Patients whose specimens were collected within 5 days of the onset of symptoms were more likely to have a viral pathogen detected than those whose specimens were collected later ( $78 \%$ versus $32 \%, p=0.002)$.

With regards to radiologic features, there were no significant differences between ICU and non-ICU patients, respectively. Only patients with influenza had more significant radiologic abnormalities than non-influenza ones $(p=0.017)$.

Patients with comorbidities ( $n=134,61 \%$ ) were significantly older compared to those with no comorbidities (median age: 59 versus $3, p=0.000)$. Additionally, they were significantly more likely to be symptomatic. The majority $(86 \%)$ of SARI-ICU patients had Charlson Age-Comorbidity Index (CACI) scores $\leq 3$ (Table 2).

Among individual viral pathogens, SARI-ICU patients with influenza virus had significantly different chronic respiratory (78\% vs $22 \%, p=0.006)$, cardiac $(33 \%$ vs $67 \%, p=0.046)$, and endocrine ( $31 \%$ vs $69 \%, p=0.023$ ) disorders than those with non-influenza SARI-ICU viral infections, respectively. For influenza vaccination history, $177 / 219$ (81\%) cases did not receive the vaccine within the 12 months prior to hospital admission, while 42/219 (19\%) were reported as unknown for an influenza vaccination status. Table 1 details these results.

\section{Clinical course, complications, and outcomes in SARI- ICU patients}

In comparison to non-ICU patients, SARI-ICU ones had sig- nificantly longer hospital stay (5 days, range 1-96, mean \pm SD $6.31 \pm 7.91$ versus 1 day, range $1-70$, mean \pm SD 3.05 $\pm 8.59 ; 95 \%$ confidence interval 5.84-16.79; $p=0.000)$. Also, ICU patients had significantly higher rates of pneumonia ( $7 \%$ vs $2 \%, p=0.022)$ than the non-ICU ones. With regards to complications, ICU patients had significantly higher rates of developing respiratory failure and ARDS ( $9 \%$ vs $0 \%$ and $6 \%$ vs $0 \%, p=0.000)$, respectively. For individual viral pathogens, RSV-ICU patients had significantly lower rates of pneumonia, respiratory failure, and ARDS, than those with non-RSV (16\% vs 84\%, 22\% vs 78\%, and 10\% vs 90\%, $p=0.000)$, as well as shorter hospital stay (median 1 day, range 1-70, mean \pm SD 3.93 \pm 7.73 versus 4 days, range $1-88$, mean \pm SD 5.40 \pm 8.97 ; $95 \%$ confidence interval $3.46-14.39 ; p=0.000$ ).

Overall mortality in SARI-ICU patients was 24/219 (11\%), peaked at $1 \%$ in 2014 , and was significantly higher than in those with non-ICU $(0 \%), p=0.000$. Overall, only $2(8 \%)$ were adults, while $22(92 \%)$ were children. Among children, 18(75\%) were aged $<5$ years. Overall, two-thirds (16/24) had comorbidities. All patients who died were mechanically ventilated. Notably, all patients who died tested positive for a viral pathogen; twelve $(50 \%)$ were positive for RSV, four (17\%) for influenza virus, two for adenovirus, one for hMPV, one for PIV and four (17\%) for mixed viral infections, respectively. Among individual viral pathogens, SARI-ICU patients with multiple viral infections had significantly lower death incidence $(10 \%$ vs $90 \%, p=0.045)$ than those with single infection (Table 1).

\section{Severe outcomes in SARI-ICU patients}

In comparison to non-ICU patients, the ICU ones had significantly severe outcomes, as indicated by illness requiring mechanical ventilation and/or resulting in death (OR 3.840, 95\% CI 0.148 14.987, $p=0.000$, and OR 1.823, 95\% CI 0.585-4.070, $p=0.000$, respectively). For individual viral pathogens, no infections were independently associated with increased severity of illness in comparison to those not infected with each of these pathogens. When analyses were stratified by age, ICU patients $<18$ years of age were

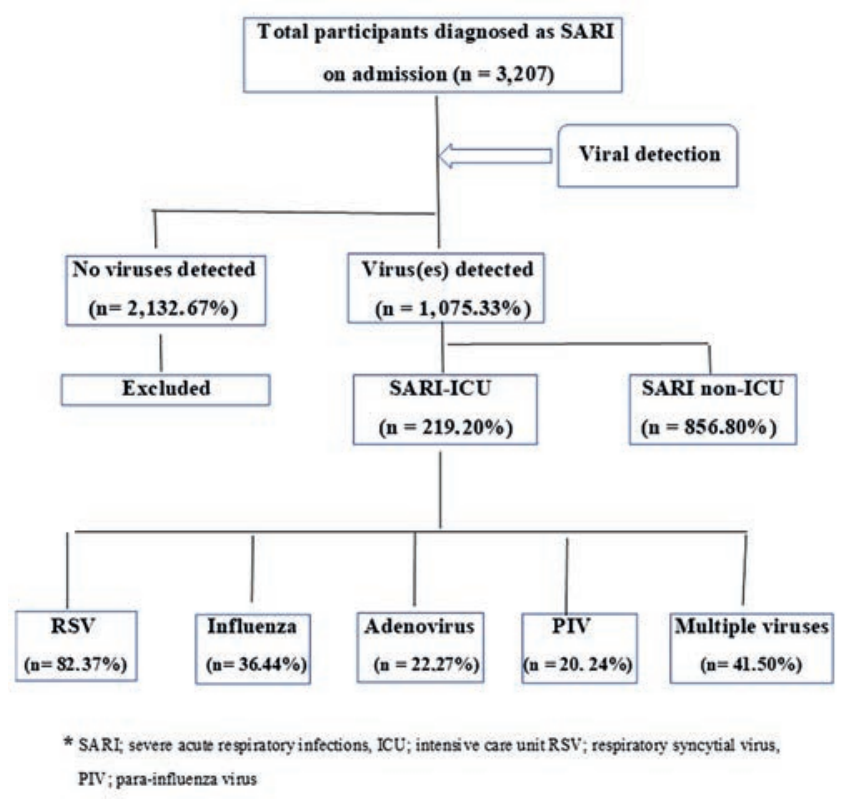

Figure 1. Flow chart of the study subjects. 
more likely than those non-ICU ones to experience a severe outcome (OR 3.437, 95\% CI 0.348-7.987, $p=0.000$ and OR 1.113, $95 \%$ CI $0.335-3.170, p=0.002$, respectively). Among ICU patients $>18$ years of age, there was no significant difference between ICU and non-ICU patients for severe outcomes, and only those adults with influenza were more likely to experience a severe outcome than those with non-influenza (OR 3.551, 95\% CI 1.148-10.987, $p=0.028$ ). Table 3 shows these details (Data for PIV, hMPV, Bocavirus, rhino-, and enterovirus are not shown in the table).

\section{Logistic regression analysis for severe outcomes}

Logistic regression analysis was used to further examine associations with severe outcomes in SARI-ICU patients with complete demographic data and clinical risk factors. By univariate analysis, individuals with multiple viral infections, CACI score $\geq 3$, radiological abnormalities, and longer hospital stay were more likely to experience a severe outcome than those with single viral infection (OR 4.362, 95\% CI 1.384-13.754, $p=0.012$ ), CACI score $<3$ (OR 9.328, 95\% CI 1.860-25.921, $p=0.020$ ), no radiological

Table 1. Demographic, clinical, and radiological characteristics of ICU and non-ICU SARI cases in Egypt, 2010-2014.

\begin{tabular}{|c|c|c|c|c|c|c|c|c|c|c|c|c|c|}
\hline Characteristic & $\begin{array}{c}\text { Non-ICU } \\
\text { SARI } \\
(\mathrm{n}=856) \\
(\%)\end{array}$ & $\begin{array}{c}\text { ICU SARI } \\
(n=219) \\
(\%)\end{array}$ & $\mathbf{p}^{*}$ & $\begin{array}{c}\text { RSV- } \\
\text { ICU } \\
(\mathrm{n}=82) \\
(\%)\end{array}$ & $\mathbf{p}^{\$}$ & $\begin{array}{c}\text { Multiple } \\
\text { viruses-ICU } \\
(\mathrm{n}=41) \\
(\%)\end{array}$ & $\mathbf{p}^{\$}$ & $\begin{array}{c}\text { PIV-ICU } \\
(n=20) \\
(\%)\end{array}$ & $\mathbf{p}^{\S}$ & $\begin{array}{l}\text { Adeno- } \\
\text { virus-ICU } \\
(\mathrm{n}=22) \\
(\%)\end{array}$ & $\mathbf{p}^{\mathbf{s}}$ & $\begin{array}{l}\text { Influenza } \\
\text { viruses-ICU } \\
(\mathrm{n}=36) \\
(\%)\end{array}$ & $\mathbf{p}^{\$}$ \\
\hline \multicolumn{14}{|c|}{ Demographics Gender } \\
\hline Female & $453 / 856(53)$ & 116/219(53) & 0.940 & $40(49)$ & 0.338 & $16(39)$ & 0.048 & $9(45)$ & 0.456 & $11(50)$ & 0.824 & $20(56)$ & 0.855 \\
\hline Male & 403/856(47) & $103 / 219(47)$ & & $42(51)$ & & $25(61)$ & & $11(55)$ & & $11(50)$ & & $16(44)$ & \\
\hline \multicolumn{14}{|c|}{ Age in years } \\
\hline Median & 0.83 & 3.00 & & 0.67 & & 1.00 & & 1.00 & & 1.00 & & 5.00 & \\
\hline (Range) & $0-74$ & $0-85$ & & $(0-85)$ & & $(0-77)$ & & $(0-74)$ & & $(0-57)$ & & $(0-76)$ & \\
\hline$<18$ years & $824 / 856(96)$ & $157 / 219(72)$ & 0.000 & $68(83)$ & 0.006 & $32(78)$ & 0.029 & $13(65)$ & 0.603 & $11(50)$ & 0.017 & $10(28)$ & 0.000 \\
\hline$>18$ years & $32 / 856(4)$ & $62 / 219(28)$ & & $14(17)$ & & $9(22)$ & & $7(35)$ & & $11(50)$ & & $26(72)$ & \\
\hline \multicolumn{14}{|c|}{ Signs and symptoms at presentation } \\
\hline Shortness of breath & $856 / 856(1)$ & $219 / 219(1)$ & NA & $82(100)$ & NA & $41(100)$ & NA & $20(100)$ & $\mathrm{NA}$ & $22(100)$ & $\mathrm{NA}$ & $36(100)$ & NA \\
\hline Sore throat & 231/856 (27) & 42/219 (19) & 0.024 & $9(11)$ & 0.080 & $7(17)$ & 0.706 & $7(35)$ & 0.074 & $6(27)$ & 0.311 & $8(22)$ & 0.614 \\
\hline Sputum production & $508 / 856(59)$ & 85/219 (39) & 0.000 & $29(35)$ & 0.243 & $15(36)$ & 0.601 & $10(50)$ & 0.374 & $9(41)$ & 0.978 & $22(61)$ & 0.009 \\
\hline Body aches & $140 / 856(16)$ & 25/219 (11) & 0.375 & $14(17)$ & 0.035 & $3(21)$ & 0.002 & $7(35)$ & 0.457 & $2(9)$ & 0.031 & $22(61)$ & 0.000 \\
\hline Tachypnea & $788 / 856(92)$ & $212 / 219(97)$ & 0.002 & $81(99)$ & 0.405 & $41(100)$ & 0.280 & $19(95)$ & 0.000 & $22(100)$ & 0.000 & $34(94)$ & 0.000 \\
\hline Nasal congestion & $577 / 856(67)$ & 70/219 (32) & 0.000 & $48(59)$ & 0.001 & $25(61)$ & 0.013 & $19(95)$ & 0.000 & $20(91)$ & 0.011 & $30(83)$ & 0.014 \\
\hline Wheezing & $732 / 856(86)$ & $149 / 219(68)$ & 0.000 & $55(67)$ & 0.031 & $31(76)$ & 0.171 & $15(75)$ & 0.571 & $22(100)$ & 0.002 & $26(72)$ & 0.022 \\
\hline Stridor & $4 / 856(0)$ & $3 / 219(1)$ & 0.119 & $5(6)$ & 0.024 & $0(0)$ & 0.001 & $1(5)$ & 0.944 & $0(0)$ & 0.034 & $18(50)$ & 0.000 \\
\hline Abnormal breath sounds & $430 / 856(50)$ & $128 / 219(58)$ & 0.053 & $30(37)$ & 0.001 & $18(44)$ & 0.199 & $12(60)$ & 0.640 & $17(77)$ & 0.016 & $26(72)$ & 0.017 \\
\hline Nausea or vomiting & $105 / 856(12)$ & $11 / 219(5)$ & 0.011 & $9(11)$ & 0.022 & $2(5)$ & 0.002 & $4(20)$ & 0.471 & $4(18)$ & 0.097 & $18(50)$ & 0.000 \\
\hline Convulsions & 92/856 (11) & $16 / 219(7)$ & 0.184 & $6(7)$ & 0.034 & $3(7)$ & 0.007 & $3(15)$ & 0.499 & $2(9)$ & 0.032 & $19(53)$ & 0.000 \\
\hline Smoking (age $\geq 12$ yrs) & $26 / 856(3)$ & 26/219 (12) & 0.034 & $6(7)$ & 0.375 & $6(14)$ & 0.604 & $3(15)$ & 0.466 & $2(9)$ & 0.878 & $9(25)$ & 0.007 \\
\hline Pregnancy & $8 / 856(1)$ & $3 / 219(1)$ & 0.974 & $0(0)$ & 0.370 & $0(0)$ & 0.062 & $1(5)$ & 0.366 & $0(0)$ & 0.838 & $2(6)$ & 0.924 \\
\hline \multicolumn{14}{|c|}{ Radiological findings } \\
\hline CXR abnormalities & 180/856 (21) & $37 / 219(17)$ & 0.088 & $12(15)$ & 0.912 & $6(14)$ & 0.923 & $3(15)$ & 0.910 & $6(27)$ & 0.211 & $10(28)$ & 0.017 \\
\hline CXR infilterates & $319 / 856(37)$ & $74 / 219(34)$ & 0.117 & $29(35)$ & 0.398 & $15(36)$ & 0.797 & $8(40)$ & 0.875 & $10(45)$ & 0.473 & $12(33)$ & 0.500 \\
\hline \multicolumn{14}{|c|}{ Clinical course } \\
\hline Pneumonia & $13 / 856(2)$ & $16 / 219(7)$ & 0.022 & $13(16)$ & 0.000 & $4(10)$ & 0.515 & $1(5)$ & 0.048 & $4(18)$ & 0.879 & $3(8)$ & 0.114 \\
\hline Mechanical ventilation & $0 / 856(0)$ & $00 / 219(46)$ & 0.000 & $43(52)$ & 0.071 & $13(32)$ & 0.047 & $8(40)$ & 0.644 & $7(32)$ & 0.000 & $17(47)$ & 0.000 \\
\hline \multicolumn{14}{|c|}{ Complications } \\
\hline Respiratory failure & 2/856 (0) & 22/21 9(10) & 0.000 & $18(22)$ & 0.000 & $4(10)$ & 0.452 & $2(10)$ & 0.702 & $4(18)$ & 0.118 & $1(3)$ & 0.417 \\
\hline ARDS & $2 / 856(0)$ & $15 / 219(7)$ & 0.000 & $8(10)$ & 0.070 & $4(10)$ & 0.752 & $0(0)$ & 0.842 & $0(0)$ & 0.175 & $0(0)$ & 0.699 \\
\hline \multicolumn{14}{|c|}{ Outcomes $^{\$}$} \\
\hline Discharged & $833 / 856(97)$ & $123 / 219(56)$ & 0.000 & $30(36)$ & 0.388 & $17(41)$ & 0.033 & $12(60)$ & 0.373 & $17(77)$ & 0.767 & $22(61)$ & 0.975 \\
\hline Transferred & 23/856 (3) & 72/219(33) & & $40(49)$ & & $20(49)$ & & $7(35)$ & & $3(14)$ & & $10(28)$ & \\
\hline Died & $0 / 856(0)$ & 24/219(11) & & $12(15)$ & & $4(10)$ & & $1(5)$ & & $2(9)$ & & $4(11)$ & \\
\hline
\end{tabular}

*Comparison between SARI-ICU and non-ICU SARI patients; $\$$ SARI-ICU patients with a positive result for that pathogen compared to a reference group of tested SARI-ICU patients with a negative result; RSV, respiratory syncytial virus; PIV, para-influenza virus; ICU, intensive care unit; ARDS, acute respiratory distress syndrome; NA, not available. 
abnormalities (OR 10.779, 95\% CI 2.195-52.945, $p=0.003$ ), and shorter hospital stay (OR 3.035, 95\% CI 1.005 -9.067, $p=0.024$ ), respectively. Multivariate analysis confirmed these results where individuals with CACI score $\geq 3$, radiological abnormalities, and longer hospital stay were more likely to experience a severe outcome than those with CACI score $<3$ (OR 7.323, 95\% CI 1.22623.022, $p=0.001$ ), no radiological abnormalities (OR 3.339, 95\% CI 1.183-9.422, $p=0.023$ ), and shorter hospital stay (OR 4.035, 95\% CI 1.011-11.060, $p=0.005$ ), respectively (Table 4 ).

\section{Discussion}

We have recently published the largest surveillance Egyptian study that addressed the epidemiological patterns of SARI due to viruses in both children and adult population and their relation to the clinical characteristics and outcomes of those patients [11]. Despite that viral pathogens were encountered in one-third of SARI patients, these infections had no negative impacts on clinical features, clinical course, and outcomes of those patients [11]. In this related study, we aimed to address the impacts of SARI on the clinical outcomes of patients admitted to the ICU, in terms of morbidity and mortality. Few studies had shed light on SARI patients admitted to the ICU $[9,10,14]$.

One-fifth of our SARI cohort needed ICU admission, the majority of whom $(72 \%)$ were children, with the highest prevalence for RSV, influenza, adenovirus, and multiple viruses $(37 \%$, $16 \%, 10 \%$, and $19 \%$ ), respectively. Forty-seven percent of SARI patients with influenza were candidates for ICU admission. These results are in accordance with those reported at different parts of the world among different SARI populations [6,7,9,10,14-16]. Among influenza-positive SARI patients, Meerhoff et al. [15] identified age $>15$ years, those having lung, heart, kidney or liver disease or being pregnant, as risk factors for ICU admission and/or fatal outcome.

Despite that $20 \%$ of our SARI patients needed ICU admission, $81 \%$ of our cohort did not receive the influenza vaccine within the
12 months prior to hospital admission. This should alert the healthcare leaders in our locality for implementing effective vaccination strategies for populations at risk for influenza.

In the current study, it seems that neither clinical signs and symptoms at presentation nor radiologic findings did help the clinician stratifying SARI patients into high-risk groups with more severe disease and/or in need for ICU admission. These data are in agreement with those reported by Wansaula and coworkers [17], which may represent a challenge to the clinicians. On the other hand, the relatively low number of SARI-ICU patients in the current study may explain this lack of association between clinical and/or radiological features and severity of the disease.

One might expect that the presence of medical comorbidities will put SARI patients into higher risk for severe disease and ICU admission. In this respect, it was also disappointing and contradicting other studies $[11,15,17]$, as it was observed that- in terms of comorbidities- there were no significant differences between ICU and non-ICU SARI patients. Definitely, studies with larger numbers of patients are needed to clarify these associations. SARI-ICU patients with influenza virus had significantly higher chronic respiratory, yet lower cardiac and endocrine disorders than those with non-influenza patients, respectively. These results support those reported by different worldwide studies [15,17-19] and highlight the importance of screening patients with those comorbidities for influenza viruses and meticulous observation for influenza-related complications and outcomes. In a study from South Africa, Cohen et al. [19] enrolled 1,376 patients with influenza-associated SARI and on multivariable analysis, they found that underlying medical conditions other than HIV were one of the important factors asso-

Table 2. Charlson Age-Comorbidity Index (CACI) scores among SARI-ICU patients $(n=219)$.

\begin{tabular}{lcc} 
& Number $(\%)$ & $\boldsymbol{p}$ \\
$\mathrm{CACI} \leq 3$ & $188(86)$ & 0.002 \\
$\mathrm{CACI}>3$ & $31(14)$ & \\
\hline
\end{tabular}

Table 3. Indicators of the severity of SARI-ICU patients by pathogen and age.

\begin{tabular}{|c|c|c|c|c|c|c|c|c|c|c|c|c|c|c|c|}
\hline & \multicolumn{3}{|c|}{ SARI-ICU cases $\$$} & \multicolumn{3}{|c|}{ RSV } & \multicolumn{3}{|c|}{ Adenovirus } & \multicolumn{2}{|r|}{ Influenza } & \multicolumn{3}{|c|}{ Multiple viruses } & \multirow[b]{2}{*}{$p^{*}$} \\
\hline & $\begin{array}{l}\text { No } \\
(\%)\end{array}$ & $\begin{array}{l}\text { OR 95\% } \\
(95 \% \text { CI) }\end{array}$ & $p^{*}$ & $\begin{array}{r}\text { No } \\
(\%)\end{array}$ & $\begin{array}{l}\text { OR 95\% } \\
(95 \% \text { CI) }\end{array}$ & $p^{*}$ & $\begin{array}{l}\text { No } \\
(\%)\end{array}$ & $\begin{array}{l}\text { OR 95\% } \\
\text { (95\% CI) }\end{array}$ & $p^{*}$ & $\begin{array}{l}\text { No } \\
(\%)\end{array}$ & $\begin{array}{l}\text { OR 95\% } \\
(95 \% \text { CI) }\end{array}$ & $p^{*}$ & $\begin{array}{r}\text { No } \\
(\%)\end{array}$ & $\begin{array}{l}\text { OR 95\% } \\
\text { (95\% CI) }\end{array}$ & \\
\hline \multicolumn{16}{|c|}{ All participants } \\
\hline Ventilation & $\begin{array}{c}100 / 219 \\
(46)\end{array}$ & $\begin{array}{c}3.84 \\
(0.148-14.987)\end{array}$ & 0.000 & $\begin{array}{c}43 / 82 \\
(52)\end{array}$ & $\begin{array}{c}0.474 \\
(0.281-1.161)\end{array}$ & 0.123 & $\begin{array}{c}7 / 22 \\
(32)\end{array}$ & $\begin{array}{c}1.486 \\
(0.613-3.601)\end{array}$ & 0.380 & $\begin{array}{r}17 / 36 \\
(47)\end{array}$ & $\begin{array}{c}1.078 \\
(0.527-2.206)\end{array}$ & 0.837 & $\begin{array}{r}13 / 41 \\
(32)\end{array}$ & $\begin{array}{c}0.486 \\
(0.236-0.998)\end{array}$ & 0.069 \\
\hline Death & $\begin{array}{c}24 / 219 \\
(11)\end{array}$ & $\begin{array}{c}1.823 \\
(0.585-4.070)\end{array}$ & 0.000 & $\begin{array}{r}12 / 82 \\
(15)\end{array}$ & $\begin{array}{c}1.194 \\
(0.378-5.167)\end{array}$ & 0.388 & $\begin{array}{r}2 / 22 \\
(9)\end{array}$ & $\begin{array}{c}0.795 \\
(0.174-3.636)\end{array}$ & 0.768 & $\begin{array}{l}4 / 36 \\
(11)\end{array}$ & $\begin{array}{c}1.019 \\
(0.326-3.180)\end{array}$ & 0.974 & $\begin{array}{l}4 / 41 \\
(10)\end{array}$ & $\begin{array}{c}0.854 \\
(0.275-2.648)\end{array}$ & 0.785 \\
\hline \multicolumn{16}{|c|}{ Children $<18$ years } \\
\hline Ventilation & $\begin{array}{c}81 / 157 \\
(52)\end{array}$ & $\begin{array}{c}3.437 \\
(0.348-7.987)\end{array}$ & 0.000 & $\begin{array}{r}36 / 68 \\
(53)\end{array}$ & $\begin{array}{c}1.100 \\
(0.585-2.070)\end{array}$ & 0.768 & $\begin{array}{l}7 / 11 \\
(64)\end{array}$ & $\begin{array}{c}1.703 \\
(0.478-6.067)\end{array}$ & 0.412 & $\begin{array}{l}5 / 10 \\
(50)\end{array}$ & $\begin{array}{c}0.934 \\
(0.259-3.364)\end{array}$ & 0.917 & $\begin{array}{r}13 / 32 \\
(40)\end{array}$ & $\begin{array}{c}0.574 \\
(0.261-1.262)\end{array}$ & 0.167 \\
\hline Death & $\begin{array}{c}22 / 157 \\
(14)\end{array}$ & $\begin{array}{c}1.113 \\
(0.335-3.170)\end{array}$ & 0.002 & $\begin{array}{r}12 / 68 \\
(18)\end{array}$ & $\begin{array}{c}1.693 \\
(0.684-4.190\end{array}$ & 0.255 & $\begin{array}{l}2 / 11 \\
(18)\end{array}$ & $\begin{array}{c}1.400 \\
(0.282-6.956)\end{array}$ & 0.681 & $\begin{array}{l}2 / 10 \\
(20)\end{array}$ & $\begin{array}{c}1.588 \\
(0.314-8.019)\end{array}$ & 0.576 & $\begin{array}{l}4 / 32 \\
(13)\end{array}$ & $\begin{array}{c}0.849 \\
(0.266-2.710)\end{array}$ & 0.783 \\
\hline \multicolumn{16}{|c|}{ Adults $>18$ years } \\
\hline Ventilation & $\begin{array}{l}19 / 62 \\
(31)\end{array}$ & $\begin{array}{c}0.283 \\
(0.189-0.424)\end{array}$ & 0.170 & $\begin{array}{l}4 / 14 \\
(29)\end{array}$ & $\begin{array}{c}2.961 \\
(0.741-5.927)\end{array}$ & 0.053 & $\begin{array}{l}3 / 11 \\
(27)\end{array}$ & $\begin{array}{c}2.202 \\
(0.579-8.383)\end{array}$ & 0.247 & $\begin{array}{l}12 / 26 \\
(46)\end{array}$ & $\begin{array}{c}3.551 \\
(1.148-10.987)\end{array}$ & 0.028 & $\begin{array}{l}0 / 9 \\
(0)\end{array}$ & $\begin{array}{c}0.791 \\
(0.678-3.922)\end{array}$ & 0.080 \\
\hline Death & $\begin{array}{c}2 / 62 \\
(3)\end{array}$ & -- & -- & $\begin{array}{l}0 / 14 \\
(0)\end{array}$ & $\begin{array}{c}0.660 \\
(0.461-3.261)\end{array}$ & 0.719 & $\begin{array}{l}0 / 11 \\
(0)\end{array}$ & $\begin{array}{c}0.817 \\
(0.724-0.921)\end{array}$ & 0.786 & $\begin{array}{l}2 / 26 \\
(8)\end{array}$ & $\begin{array}{c}0.400 \\
(0.293-0.545)\end{array}$ & 0.339 & $\begin{array}{l}0 / 9 \\
(0)\end{array}$ & $\begin{array}{c}0.850 \\
(0.764-0.945)\end{array}$ & 0.671 \\
\hline
\end{tabular}

*Comparison between SARI-ICU and non-ICU SARI patients; \$SARI-ICU patients with a positive result for that pathogen compared to a reference group of tested SARI-ICU patients with a negative result; RSV, respiratory syncytial virus; ICU, intensive care unit. Severe outcome is defined as illness requiring ventilation or resulting in death. 
ciated with death (OR 2.9, 95\% CI 1.2.7.3, $p=0.021)$.

Comparing the clinical course, complications, and outcomes between SARI-ICU and non-ICU patients revealed interesting results. SARI-ICU patients had significantly higher rates of hospital stay, pneumonia, respiratory failure and ARDS, and mortality.

Previous studies showed conflicting results on the impacts of viral infections on clinical outcomes in both patients with SARI $[7,9,11,15,17]$ and those with SARI-ICU $[7,9,10,15,16,19]$. Differences in patients' numbers, enrollment criteria, and laboratory methodologies could explain these results. Moreover, our results confirm that although PCR has been established as a reliable diagnostic assay with high sensitivity and specificity for respiratory viruses, particularly for RSV [20], the clinical implications of such positive laboratory results are still less clear [14].

Our data showed a mortality rate of $11 \%$, the majority of which $(92 \%)$ was reported among children, $75 \%$ of the later were aged $<5$ years. Notably, all patients who died tested positive for a viral pathogen, $50 \%$ were positive for RSV. Our findings may contradict those observed by Sakr and colleagues [10], who reported ICU and in-hospital mortality rates of 20.2 and $27.2 \%$, in 663 SARI patients, respectively. Despite that the authors reported a viral etiology of only $7.7 \%$ in their SARI patients, organ failure occurred in $74.7 \%$ of patients in the ICU, and this could explain these high mortality rates. Our mortality data underscore those in previous reports denoting that RSV is a well-established respiratory virus known to cause severe disease by itself, especially in younger children $[6,11,16,21]$.

Data analysis of severe outcomes among our SARI-ICU patients appears to be interesting. SARI-ICU patients had significantly severe outcomes, in comparison to those non-ICU ones, in terms of illness requiring mechanical ventilation and/or resulting in death, which remained significant among children but not adults (except for those with influenza). Multivariate logistic regression analysis revealed that higher Charlson Age-Comorbidity Index scores, radiological abnormalities, and longer hospital stay are risk factors for severe outcomes among SARI-ICU patients. Sakr et al. [10] observed that organ failure occurred in $74.7 \%$ of SARI patients in the ICU, and it was mostly respiratory $(53.8 \%)$, cardiovascular (44.5\%), and renal (44.6\%), respectively. Adding to the dilemma of our findings, it seems logical that SARI-ICU patients with respiratory comorbidities and longer hospital stay are more vulnerable to severe outcomes, yet no individual viral pathogen was associated with severe outcomes of those patients.

Despite that, our data for severe outcomes could be counterintuitive, as various studies have indicated that higher viral loads among SARI patients are related to more severe disease and locally increased cytokine production [6,9,17,22-24]. However, other studies failed to replicate this finding $[11,14,16,25,26]$. Our findings may have been influenced by the selection of hospitalized and seriously ill patients and/or the use of PCR for assessment of the

Table 4. Logistic regression for predictors of severe outcomes among SARI-ICU cases.

\begin{tabular}{|c|c|c|c|c|c|}
\hline & & Univar & & Multivaria & \\
\hline & & OR $(95 \% \mathrm{CI})$ & $p$ & OR $(95 \% \mathrm{CI})$ & $P$ \\
\hline RSV & $\begin{array}{l}\text { Negative } \\
\text { Positive }\end{array}$ & $\begin{array}{l}\text { ref } \\
0(0)\end{array}$ & 1.000 & & \\
\hline Adenovirus & $\begin{array}{l}\text { Negative } \\
\text { Positive }\end{array}$ & $\begin{array}{c}\text { ref } \\
0.294(0.073-1.176)\end{array}$ & 0.084 & & \\
\hline Rhinovirus & $\begin{array}{l}\text { Negative } \\
\text { Positive }\end{array}$ & $\begin{array}{c}\text { ref } \\
1.225(0.053-2.052)\end{array}$ & 0.899 & & \\
\hline Influenza & $\begin{array}{l}\text { Negative } \\
\text { Positive }\end{array}$ & $\begin{array}{c}\text { ref } \\
3.584(0.075-11.040)\end{array}$ & 0.057 & & \\
\hline PIV & $\begin{array}{l}\text { Negative } \\
\text { Positive }\end{array}$ & $\begin{array}{c}\text { ref } \\
1.025(0.284-3.696)\end{array}$ & 0.970 & & \\
\hline Multiple viruses & $\begin{array}{l}\text { Single virus } \\
\text { Multiple viruses }\end{array}$ & $\begin{array}{c}\text { ref } \\
4.362(1.384-13.754)\end{array}$ & 0.012 & $\begin{array}{c}\text { ref } \\
2.394(1.009-5.681)\end{array}$ & 0.055 \\
\hline Age & $\begin{array}{l}\text { Adults }>18 \text { years } \\
\text { Children }<18 \text { years }\end{array}$ & $\begin{array}{c}\text { ref } \\
1.749(0.324-9.428)\end{array}$ & 0.516 & & \\
\hline Gender & $\begin{array}{l}\text { Male } \\
\text { Female }\end{array}$ & $\begin{array}{c}\text { ref } \\
0(0)\end{array}$ & 0.999 & & \\
\hline Smoking & $\begin{array}{l}\text { No } \\
\text { Yes }\end{array}$ & $\begin{array}{c}\text { ref } \\
2.624(0.458-15.046)\end{array}$ & 0.279 & & \\
\hline $\mathrm{CACI}$ & $\begin{array}{l}\leq 3 \\
>3\end{array}$ & $\begin{array}{c}\text { ref } \\
9.328(1.860-25.921)\end{array}$ & 0.020 & $\begin{array}{c}\text { ref } \\
7.323(1.226-23.022)\end{array}$ & 0.001 \\
\hline Pneumonia & $\begin{array}{l}\text { None } \\
\text { Any }\end{array}$ & $\begin{array}{c}\text { ref } \\
1.559(0.313-7.770)\end{array}$ & 0.588 & ref & \\
\hline Radiologic abnormalities & $\begin{array}{l}\text { None } \\
\text { Any }\end{array}$ & $\begin{array}{c}\text { ref } \\
6.332(1.095-12.645)\end{array}$ & 0.004 & $3.339(1.183-9.422)$ & 0.023 \\
\hline Respiratory failure & $\begin{array}{l}\text { No } \\
\text { Yes }\end{array}$ & $\begin{array}{c}\text { ref } \\
0.937(0.015-2.243)\end{array}$ & 0.077 & & \\
\hline ARDS & $\begin{array}{l}\text { No } \\
\text { Yes }\end{array}$ & $\begin{array}{c}\text { ref } \\
2.461(0.075-18.055)\end{array}$ & 0.613 & & \\
\hline Length of hospital stay & $\begin{array}{l}\text { None } \\
\text { Any }\end{array}$ & $\begin{array}{c}\text { ref } \\
8.035(2.005-19.067)\end{array}$ & 0.025 & $\begin{array}{c}\text { ref } \\
4.035(1.011-11.060)\end{array}$ & 0.005 \\
\hline
\end{tabular}

ICU, intensive care unit; RSV, respiratory syncytial virus, PIV, parainfluenza virus; CACI, Charlson Age-Comorbidity Index; ARDS, acute respiratory distress syndrome; OR, odds ratio. 
viral load. Moreover, viral load may be one of many factors that could be related to disease severity. In this regards the role of a deleterious or counter-productive immune response may be another factor related to disease severity, which has been the subject of several studies $[27,28]$.

Finally, the current study has many points of strength; it was the first surveillance that addresses the clinical impacts of viruses causing SARI in the ICU in both children and adult Egyptian population, with enrolled large numbers of patients and over a relatively long period. Moreover, analyses of homogenous populations, rather than different ethnic groups [17], give the results reliable and strong support. On the other hand, it has some limitations; it reflects an experience of one tertiary care center only, and the flu vaccine was not used.

\section{Conclusions}

Viral pathogens were encountered in one-third of hospitalized adult and pediatric Egyptian patients with SARI and 20\% of them were admitted to the ICU. In comparison to non-ICU patients, SARI-ICU ones had neither significantly predominant clinical signs and symptoms nor radiological features. The presence of chronic respiratory, cardiac, and endocrine disorders negatively affects SARI-ICU patients with influenza. Higher comorbidity index scores, radiological abnormalities, and longer hospital stay are risk factors for severe outcomes in SARI-ICU patients in our locality. Further studies are warranted.

\section{Acknowledgments}

The authors thank the nursing team at Cairo University Hospitals (CUH) and the technician teams of the laboratory departments of $\mathrm{CUH}$ and the Naval Medical Research Unit No.3 (NAMRU-3) for their contribution to this work.

$\begin{array}{ll}\text { Abbreviations } \\ \text { ARDS } & \text { acute respiratory distress syndrome; } \\ \text { ARIs } & \text { acute respiratory infections; } \\ \text { CACI } & \text { Charlson Age-Comorbidity Index; } \\ \text { CDC } & \text { Center of Disease Control; } \\ \text { CUH } & \text { Cairo University Hospital; } \\ \text { HBOV } & \text { human Bocavirus; } \\ \text { hMPV } & \text { human metapneumovirus; } \\ \text { Ig } & \text { immunoglobulin; } \\ \text { ILI } & \text { Influenza like illness; } \\ \text { IQR } & \text { interquartile range; } \\ \text { NP } & \text { nasopharyngeal; } \\ \text { OP } & \text { oropharyngeal; } \\ \text { OR } & \text { odds ratio; } \\ \text { PIV } & \text { parainfluenza virus; } \\ \text { RSV } & \text { respiratory syncytial virus; } \\ \text { RT qPCR } & \text { quantitative real-time reverse transcription polymerase } \\ & \text { chain reaction; } \\ \text { SARI } & \text { severe acute respiratory infection; } \\ \text { VTM } & \text { viral transport medium; } \\ \text { WHO } & \text { World Health Organization. }\end{array}$

\section{References}

1. World Health Organization. WHO pandemic influenza draft protocol for rapid response and containment, 2006. WHO, Geneva.

2. World Health Organization. Chapter 7: a Cough or Difficulty Breathing. Handbook IMCI Integrated management of childhood illness. Available from: https://apps.who.int/iris/ handle/10665/42939

3. World Health Organization. WHO global technical consultation: global standards and tools for influenza surveillance. Available from: https://www.who.int/influenza/resources/documents/technical_consultation/en/

4. World Health Organization. WHO surveillance case definitions for ILI and SARI. 2014. Available from: https://www.who.int/influenza/surveillance_monitoring/ili_sar i_surveillance_case_definition/en/

5. Al-Toum R, Bdour S, Ayyash H. Adenovirus infections in Jordanian hospitalized pediatric patients: Prevalence and clinical features. Jordan Med J 2009;43:171-9.

6. El Kholy AA, Mostafa NA, El-Sherbini SA, Ali AA, Ismail RI, Magdy RI,et al. Morbidity and outcome of severe respiratory syncytial virus infection. Pediatr Int 2013;55:283-8.

7. El Kholy AA, Mostafa NA, Ali AA, El-Sherbini SA, Ismail RI, Magdy RI, et al. Risk factors of prolonged hospital stay in children with viral severe acute respiratory infections. J Infect Dev Ctries 2014;8:1285-93.

8. Ruuskanen O, Lahti E, Jennings LC, Murdoch DR. Viral pneumonia. Lancet 2011;377:1264-75.

9. Remolina YA, Ulloa MM, Vargas H, Díaz L, Gómez SL, Saavedra A, et al. Viral infection in adults with severe acute respiratory infection in Colombia. PLoS One 2015;10 e0143152.

10. Sakr Y, Ferrer R, Reinhart K, et al. The Intensive Care Global Study on Severe Acute Respiratory Infection (IC-GLOSSARI): a multicenter, multinational, 14-day inception cohort study. Intensive Care Med 2016;42:817-88.

11. Hatem A, Mohamed S, Abu Elhassan UE, Ismael EAM, Rizk MS, El-Kholy A, El-Harras M, et al. Clinical characteristics and outcomes of patients with severe acute respiratory infections (SARI): Results from the Egyptian Surveillance Study 2010-2014. Multidiscip Respir Med 2019:14:11. doi: 10.1186/s40248-019-0174-7

12. Charlson M, Szatrowski TP, Peterson J, Gold J. Validation of a combined comorbidity index. J Clin Epidemiol 1994;47:124551.

13. World Health Organization. WHO information for molecular diagnosis of influenza virus - update. Available from: https://www.who.int/influenza/gisrs_laboratory/molecular_dia gnosis/en/

14. Horton KC, Dueger EL, Kandeel A, Abdallat M, El-Kholy A, Al- S, al. Viral etiology, seasonality and severity of hospitalized patients with severe acute respiratory infections in the Eastern Mediterranean Region, 2007-2014. PLoS One 2017; 12:e0180954.

15. Meerhoff TJ, Simaku A, Ulqinaku D, Torosyan L, Gribkova N, Shimanovich V, et al. Surveillance for severe acute respiratory infections (SARI) in hospitals in the WHO European regionan exploratory analysis of risk factors for a severe outcome in influenza-positive SARI cases. BMC Infect Dis 2015;15:1.

16. Moesker FM, van Kampen JJ, van Rossum AMC, de Hoog M, Koopmans MPG, Osterhaus ADME, et al. Viruses as sole causative agents of severe acute respiratory tract infections in children. PLoS One 2016;11:e0150776.

17. Wansaula Z, Olsen SJ, Casal MG, Golenko C, Erhart LM, 
Kammerer P, et al. Surveillance for severe acute respiratory infections in Southern Arizona, 2010-2014. Influenza Other Respir Viruses 2016;10:161-9.

18. Breiman RF, Cosmas L, Njenga MK, Williamson J, Mott JA, Katz MA, et al. Severe acute respiratory infection in children in a densely populated urban slum in Kenya, 2007-2011. BMC Infect Dis 2015;15:95.

19. Cohen C, Moyes J, Tempia S, Groome M, Walaza S, Pretorius $\mathrm{M}$, et al. Mortality amongst patients with influenza-associated severe acute respiratory illness, South Africa, 2009-2013. PLoS One 2015;10:e0118884.

20. Henrickson KJ, Hall CB. Diagnostic assays for respiratory syncytial virus disease. Pediatr Infect Dis J 2007;26: S36-40.

21. Hall CB, Weinberg GA, Iwane MK, Blumkin AK, Edwards $\mathrm{KM}$, Staat MA, et al. The burden of respiratory syncytial virus infection in young children. N Engl J Med 2009;360:588-98.

22. Falsey AR, Criddle MC, Walsh EE. Detection of respiratory syncytial virus and human metapneumovirus by reverse transcription polymerase chain reaction in adults with and without respiratory illness. J Clin Virol 2006;35:46-50.

23. Hasegawa K, Jartti T, Mansbach JM, Laham FR, Jewell AM, Espinola JA, et al. Respiratory syncytial virus genomic load and disease severity among children hospitalized with bronchi- olitis: Multicenter cohort studies in the United States and Finland. J Infect Dis 2014;211:1550-9.

24. Jansen RR, Wieringa J, Koekkoek SM, Visse CE, Pajkrt D, Molenkamp R, et al. Frequent detection of respiratory viruses without symptoms: toward defining clinically relevant cutoff values. J Clin Microbiol 2011;49:2631--6.

25. Adams O, Weis J, Jasinska K, Vogel M, Tenenbaum T. Comparison of human metapneumovirus, respiratory syncytial virus and rhinovirus respiratory tract infections in young children admitted to hospital. J Med Virol 2015;87:275-80.

26. Oshansky CM, Gartland AJ, Wong SS, Jeevan T, Wang D, Roddam PL, et al. Mucosal immune responses predict clinical outcomes during influenza infection independently of age and viral load. Am J Respir Crit Care Med 2014;189:449-62.

27. Vandini S, Bottau P, Faldella G, Lanari M. Immunological, viral, environmental, and individual factors modulating lung immune response to respiratory syncytial virus. Biomed Res Int 2015;2015:875723.

28. Viasus D, Paño-Pardo JR, Cordero E, Campins A, LópezMedrano F, Villoslada A, et al. Effect of immunomodulatory therapies in patients with pandemic influenza A (H1N1) 2009 complicated by pneumonia. J Infect 2011;62:193-9. 